\title{
Radiation-induced skin reactions: mechanism and treatment
}

\author{
Jinlong Wei' \\ Lingbin Meng ${ }^{2}$ \\ Xue Hou' \\ Chao Qu' \\ Bin Wang' \\ Ying $\mathrm{Xin}^{3}$ \\ Xin Jiang' \\ 'Department of Radiation Oncology, \\ The First Hospital of Jilin University, \\ Changchun I3002I, China; \\ ${ }^{2}$ Department of Internal Medicine, \\ Florida Hospital, Orlando, FL 32803 , \\ USA; ${ }^{3}$ Key Laboratory of Pathobiology, \\ Ministry of Education, Jilin University, \\ Changchun I3002I, China
}

This article was published in the following Dove Medical Press journal: Cancer Management and Research

\begin{abstract}
Radiotherapy (RT) is a major treatment for malignant tumors. The latest data show that $>70 \%$ of patients with malignant tumors need RT at different periods. Skin changes can be experienced by up to $95 \%$ of patients who underwent RT. Inflammation and oxidative stress (OS) have been shown to be generally associated with radiation-induced skin reactions (RISRs). Inflammatory response and OS interact and promote each other during RISRs. Severe skin reactions often have a great impact on the progress of RT. The treatment of RISRs is particularly critical because advanced RT technology can also lead to skin reactions. RISRs are classified into acute and chronic reactions. The treatment methods for acute RISRs include steroid treatment, creams, ointments, and hydrocolloid dressings, depending on the reaction grading. Chronic RISRs includes chronic ulcerations, telangiectasias, and fibrosis of the skin, and advanced treatments such as mesenchymal stem cells, hyperbaric oxygen therapy, superoxide dismutase, and low-intensity laser therapy can be considered. Here, we review and summarize the important mechanisms that cause RISRs as well as the standard and advanced treatments for RISRs.
\end{abstract}

Keywords: radiation-induced skin reactions, inflammatory response, oxidative stress, treatment

\section{Introduction}

Radiotherapy (RT) is the primary treatment for many cancers, and it can damage the healthy tissues in both short and long term. The latest data show that $>70 \%$ of patients with malignant tumors need RT. Radiation-induced skin reaction (RISR) is one of the main adverse effects. Acute RISRs may have severe sequelae, affecting the quality of life and the progress of cancer treatment. The main factors affecting patients' quality of life include pain and discomfort caused by RISRs. ${ }^{1}$ Therefore, it is crucial to alleviate or even eradicate the radiation-induced adverse events. ${ }^{2}$

RISRs are often assessed as acute and chronic and classified on a scale of 1-4 on the basis of the Common Terminology Criteria for Adverse Events v3.0. Grade 1 changes include dry desquamation with generalized erythema. Grade 2 changes include brisk erythema or patchy moist desquamation. When the cumulative radiation dose reaches 40 Gy or higher, moist desquamation occurs at the folds of the skin. ${ }^{3}$ Grade 3 changes include extensive moist desquamation outside of the skin folds. Grade 4 changes include ulcers, bleeding, and skin necrosis. ${ }^{4}$ The chronic radiation-induced reactions include chronic ulcerations and wounds, fibrosis, telangiectasias, secondary skin cancers, and radiation-induced keratoses. ${ }^{5}$ Chronic RISRs are true late-stage reactions that take months to years to develop after exposure to ionizing radiation (IR). ${ }^{4}$ 
These chronic effects are more dependent on the type, area, volume, fraction size, and schedule of radiation rather than total radiation dose. ${ }^{6}$

Many factors increasing the risk of acute RISRs have been identified. The severity of the reactions is related to both internal and external factors. External factors include the total radiation dose, fractioned delivery schedules, volume of irradiated tissue, and the internal radiosensitivity of the involved tissue. ${ }^{7}$ Genetics influences the development of acute RISRs, particularly conditions resulting from mutations in DNA repair mechanisms. Ataxia telangiectasia is closely related to the mutation of $A T M$ gene. ${ }^{8}$ Patients with the disease are more likely to develop serious complications after RT because they cannot repair their DNA. Many clinical trials have attempted to study the relationship between radiosensitivity and radiation-associated complications. ${ }^{9-11}$

The mechanisms associated with RISRs include inflammatory response and oxidative stress (OS). Inflammatory response and OS interact and promote each other. ${ }^{12,13}$ After radiation-induced cell damage, cells die in various forms, especially mitotic death, leading to inflammation and chronic OS. In chronic phases, inflammation and OS can lead to changes in various cytokines, cell cycle changes, and DNA damage, sustaining the cascade leading to late reactions. Treatment is based on the severity of acute RISRs. Treatments are incorporated into wound care management to maintain a moist environment to speed up recovery. Permanence, gradualness, and irreversibility are a unique subset of the adverse effects of RT in chronic RISRs; fibrosis of the skin and soft tissue may progress from months to years after the treatment. ${ }^{14}$ Chronic RISRs have a significant impact on the quality of life because of the irreversibility of the damage. ${ }^{15}$

In this review, we summarize the important mechanisms that cause RISRs as well as some standard treatments and advanced innovative treatments for acute and chronic RISRs.

\section{Mechanism of RISRs}

\section{Inflammatory response}

Inflammatory response has been shown to be generally associated with RISRs. ${ }^{12}$ In the initial period of RT, there is an immediate generation of an inflammatory response. The early inflammatory response to radiation is mainly caused by pro-inflammatory cytokines (IL-1, IL-3, IL-5, IL-6, and tumor necrosis factor $[\mathrm{TNF}]-\alpha$ ), chemokines (eotaxin and IL-8), receptor tyrosine kinase, and adhesions molecules (intercellular adhesion molecule 1 [ICAM-1], E-selectin, and vascular cell adhesion protein). These factors can create a local inflammatory response of eosinophils and neutrophils, leading to self-perpetuating tissue damage and loss of protective barriers ${ }^{16}$ (Figure 1). Janko et al ascertained that IL-1 had an important role in the development of RISRs. They found that mice that lack either IL-1 or the IL-1 receptor developed less inflammation and less severe pathological changes in their skin, especially at later time points. This study provided a potential therapeutic targeting of IL-1 for the remission of RISRs. The production of IL-1 in skin is mainly regulated by monocytes, macrophages, fibroblasts, keratinocytes, and many other immune mediators. ${ }^{17}$ In the acute phase, all resident cells, including keratinocytes, fibroblasts, and endothelial cells, respond to IR by the activation of the early response genes and proteins, which include a lot of growth factors, chemokines, and cytokines. These various growth factors then attract inflammatory cells that participate in the second phase of RISRs.

Nucleotide-binding domain, leucine-rich repeat-containing family, pyrin domain-containing 3 (NLRP3) inflammasome upregulation at the expression or activation level has been reported to play an important role in radiation damage including RISRs in recent years. ${ }^{18-20}$ NLRP3 inflammasome is a multi-protein complex that activates caspase-1, which leads to the maturation of the pro-inflammatory cytokines IL-1 $\beta$ and IL-18. ${ }^{21}$ The study by Allam et $\mathrm{al}^{22}$ showed that radiation-induced mitochondrial apoptosis can lead to the release of oxidative mitochondrial DNA into the cytoplasm and bound it to NLRP3 inflammasome in the cytosol, which causes activation of the NLRP3 inflammasome (Figure 1).

The development of radiation-induced fibrosis is also mediated by inflammation, which begins immediately after RT and continues for months to years. ${ }^{14}$ TNF- $\alpha$, IL- 6 , and IL-1 are involved in the inflammatory response, while TGF- $\beta$ and platelet-derived growth factor regulate fibroblast activity and promote the production of extracellular matrix proteins. ${ }^{23}$ Fibroblasts are the key cells in the development of late radiation-induced fibrotic changes. ${ }^{24}$ Permanently atypical fibroblasts can cause skin atrophy, contraction, and fibrosis. ${ }^{25}$ The TGF- $\beta$ is a regulatory protein that controls wound healing, proliferation, and differentiation of multiple cell types and synthesis of extracellular matrix proteins in the normal tissue inflammatory response. ${ }^{26}$ Its main function on connective tissues in vivo is to promote growth. The proliferation of endothelial cell is also stimulated, but the growth of epithelial cell is inhibited. Mice lacking a downstream mediator of TGF- $\beta$, Smad3, demonstrated reduced tissue damage and fibrosis after irradiation and accelerated healing. ${ }^{27}$ Although TGF- $\beta$ is known as a central player in the fibrotic process, other cytokines and growth factors such 


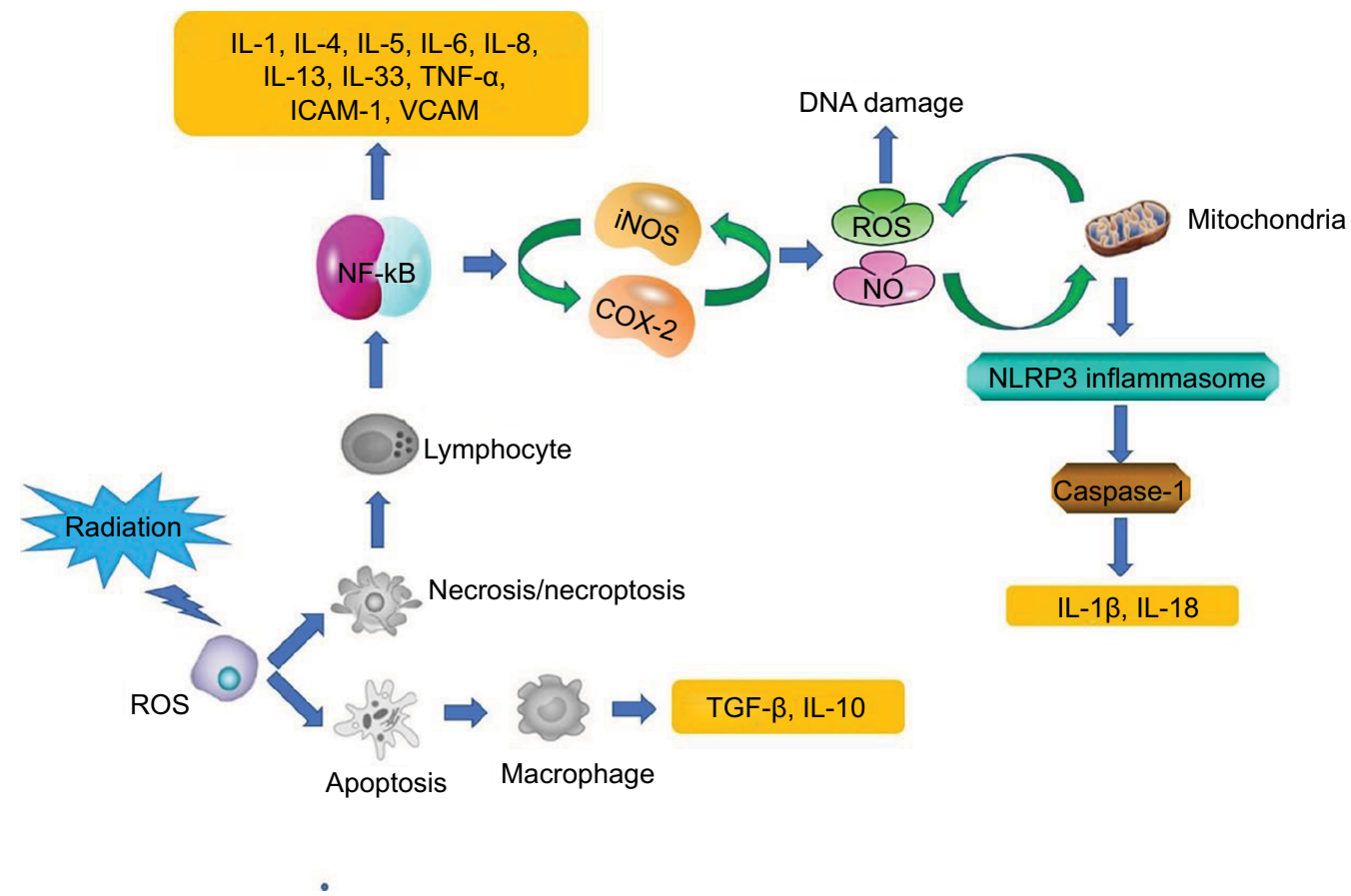

Figure I Mechanisms associated with RISRs: inflammation and oxidative stress.

Abbreviations: COX-2, cyclooxygenase 2; ICAM-I, intercellular adhesion molecule I; iNOS, inducible nitric oxide synthase; NF-kB, nuclear factor kB; NLRP3, nucleotidebinding domain, leucine-rich repeat-containing family, pyrin domain-containing 3; NO, nitric oxide; RISR, radiation-induced skin reaction; TNF, tumor necrosis factor; VCAM, vascular cell adhesion protein.

as insulin-like growth factor 1 and connective tissue growth factors (CTGFs) are involved in this process in the skin ${ }^{24}$ (Figure 1).

Inhibition of pro-inflammatory cytokines such as MCP-1 and cyclooxygenase 2 (COX-2) can improve skin tolerance to $\mathrm{RT}^{28}$ Some studies have also reported COX-2 to be an important gene mediating the subsequent inflammation. ${ }^{29}$ The study by Cheki et al ${ }^{30}$ showed that inhibition of COX-2 by celecoxib can reduce inflammation of the dermis, MCP-1 mRNA expression, and RISRs.

\section{Oxidative stress}

Chronic OS participates in the development of several diseases, including late RISRs. The redox system plays a key role in the early and late effects of RISRs. ${ }^{31,32}$

Because $80 \%$ of the tissues and cells are made of water, much of the radiation damage from exposure to low linear energy transfer radiation (X rays, $\gamma$ rays, and fast electrons) is due to radiolysis of water leading to the generation of ROS and reactive nitrogen species (RNS). ${ }^{33}$ During normal cell function, ROS and RNS are important mediators for some cellular processes such as immune response, cell signaling, microbial defenses, differentiation, cell adhesion, and apoptosis. ${ }^{34}$ The ROS and RNS are the major sources of normal tissue damage after exposure to IR. The production of ROS undergoes molecular changes, damaging DNA, lipids, and proteins and activating early-response transcription factors and signal transduction pathways. ${ }^{35}$ As a result, it causes damage to the skin tissue (Figure 1).

Free radicals generated by IR upregulate the COXs, NOS, LOXs, and NADPH oxidase. Their effected changes in mitochondrial functions are markedly noticeable. Each of these enzymes is expressed differently in multiple cells, tissues, and organs in a specific way. NADPH oxidase is a membrane-bound oxidoreductase that transfers an electron from NADPH to the oxygen molecule. Several subtypes of these enzymes have been found in the cells ${ }^{31}$; NOX1-5, DUOX1, and DUOX2 are the most important subtypes of NADPH oxidase enzymes involved in respiratory burst after exposure to radiation. ${ }^{36}$ These enzymes are highly stable and continuously produce ROS following exposure. Each of these enzymes is activated in a specific type of cellular tissue. In addition, enzymes can be stimulated by a large number of stressors and stimuli, as well as different types of cytokines and growth factors. A large number of inflammatory cytokines, chemokines, and hormones, such as IL-1, TNF- $\alpha$, TGF- $\beta$, interferon (IFN)- $\gamma$, and angiotensin II are a part of the NOX system activation. ${ }^{37}$

Nitric oxide (NO) has many targets within cells. Under stress conditions, such as inflammation, inducible nitric 
oxide synthase (iNOS) is the main source of NO and plays a key role in the process of OS and carcinogenesis. NO is produced by macrophages via iNOS enzyme in response to inflammatory stimulation. It is highly reactive and interacts with the mitochondria-derived superoxide to form more reactive peroxynitrite. However, high level of $\mathrm{NO}$ competes with $\mathrm{O}_{2}$ in the electron transport chain, which may inhibit respiration in the mitochondria. This effect may lead to an increase in superoxide generation, which amplifies the OS. ${ }^{38}$ The study by Ohta et al ${ }^{39}$ suggested that increased level of NO has a direct relation with radiation dose. In addition, they observed elevated levels of NO in the early hours after exposure (Figure 1).

Inflammation plays a key role in redox activation. Direct exposure of normal cells to IR or ROS leads to nuclear and mitochondrial DNA damages, which may result in cell death through apoptosis, mitotic catastrophe, and necrosis. ${ }^{40} \mathrm{Cell}$ apoptosis can trigger the release of anti-inflammatory cytokines such as IL-10 and TGF- $\beta$, while necrosis may cause the release of pro-inflammatory cytokines such as IL-1, IL-6, IL-8, IL-13, IL-33, and TNF- $\alpha$ and other inflammatory mediators. ${ }^{41}$ Chronic inflammation can persist long after exposure without the immune system suppressing these reactions. This is associated with chronic oxidative damage, which causes genomic instability and damage to the normal function of the skin tissue ${ }^{42}$ (Figure 1).

Understanding the mechanisms of chronic oxidative damage and injury of affected cells, tissues, and organs after exposure to IR may contribute to the development of treatment and management strategies of the complications associated with RT. ${ }^{31}$

\section{Genomic etiology}

DNA damage and response to IR are critical for understanding potential complications in normal tissues. With the first dose of RT, there is immediate tissue damage, production of short-lived free radicals, and irreversible breaks in cellular DNA. ${ }^{43}$ IR induces single-strand and double-strand DNA breaks (DSBs). Most single-strand breaks can be repaired, while DSBs result in cell death. Exposure to high doses of IR can produce massive DNA damage in cells. Accumulation of unrepaired DNA damage can lead to the induction of deletion, mutations, chromosome aberrations, or cell death. ${ }^{44}$

DNA repair system plays a key role in normal tissue tolerance to RT. There is a predictable increase in regulation of DNA repair genes after radiation exposure. Inflammation and OS may inhibit DNA damage repair. There is evidence that chronic inflammation lead to suppression of DNA repair response and mutations in tumor suppressor genes and oncogenes.$^{45} \mathrm{NO}$ produced by immune cells including macrophages and neutrophils can inhibit DNA repair and alter the expression of certain genes. ${ }^{46}$

Understanding radiation-induced DNA damage and DNA repair system may contribute to the development of adjuncts to RT.

\section{Therapy of RISRs Topical corticosteroids}

Acute RISRs is an inflammatory reaction and is usually treated with topical corticosteroids. Topical corticosteroids have therapeutic effects because of their anti-inflammation, immunosuppression, anti-proliferation, and vasoconstriction characteristics. ${ }^{47}$ The anti-inflammatory effects of corticosteroids are often achieved through vasoconstriction, reduced capillary permeability, and inhibition of leukocyte proliferation and migration, but the mechanism is not completely understood. ${ }^{48}$ The inflammatory process in acute radiation is partially controlled by pro-inflammatory cytokines; IL-6 is considered as one of the key mediators of radiation-induced inflammation..$^{49,50}$ Beetz et al ${ }^{51}$ reported an upregulation of IL-6 expression in irradiated human epithelial cell lines, which could be inhibited by corticosteroids. Topical corticosteroids block inflammation by targeting cytokines and proteins, such as reducing the production of IL-1, IL-2, IFN$\gamma, \mathrm{TNF}-\alpha$, and granulocyte-macrophage colony-stimulating factor. ${ }^{47}$

Another substance possibly targeted by topical corticosteroids in RISRs is histamine. Moriyasu et al demonstrated that histamine was involved in the development of radiation-induced erythema and edema. They observed that the irradiation of skin of mast cell-deficient mice never led to erythema and edema and that blockage of $\mathrm{H} 1$ receptors with antihistamine inhibited erythema and edema induced by gamma irradiation. ${ }^{52}$ The long-term application of topical steroids ( $>6$ weeks) has been shown to decrease histamine and deplete mast cells on skin. ${ }^{53}$

Mometasone furoate (MMF) is a highly potent corticosteroid. Irradiated skin samples treated with topical mometasone showed a significant decrease in the pro-inflammatory mediators. ${ }^{28} \mathrm{~A}$ randomized trial assessed the effect of MMF on acute skin-related toxicity in patients accepting breast or chest wall RT. The results suggested that the patients receiving daily MMF treatment during RT might experience reduced acute dermal toxicity compared to the patients receiving placebo. ${ }^{54}$ Another randomized trial demonstrated that the 
preventive and sustained use of $0.1 \%$ methylprednisolone was better for relieving skin damage caused by radiation therapy than the topical dexpanthenol emollients. ${ }^{55}$ Another study showed that the preventive and sustained use of $0.1 \%$ betamethasone during breast cancer chest wall RT delayed the onset of acute radiation dermatitis. ${ }^{56} \mathrm{~A}$ randomized study with betamethasone and two moisturizing creams showed that the control of acute radiation dermatitis with betamethasone cream for breast cancer adjuvant RT was more effective than the moisturizers. ${ }^{57}$

In the future, topical corticosteroids may be the first-line treatment for the patients undergoing RT to prevent moist desquamation.

\section{Creams and ointments}

Trolamine-containing topical emulsions have a history of use for radiation dermatitis, with information on their mechanistic role already reviewed. ${ }^{4}$ They can remove necrotic tissue, accelerate fibroblast proliferation, reduce vascular changes in vitro, restore CD34 expression, accelerate epithelial cell proliferation, and reduce IL-1 secretion. ${ }^{4}$ Triethanolamine has been used in clinical practice for $>30$ years to manage a variety of diseases that affect skin integrity, such as radiation dermatitis and skin wounds..$^{58}$ No major adverse reactions have been reported with topical emulsions containing triethanolamine. Local tolerability is good, and the potential risk of skin irritation is low. ${ }^{59}$

Biafine is an oil-in-water topical emulsion containing triethanolamine, approved by the Food and Drug Administration for use in a variety of wound healing environments, including minor abrasions to full-thickness wounds, superficial partialthickness empyrosis, and radiation dermatitis. ${ }^{60}$ Application of biafine in a human epidermal wound model showed that wound healing is promoted by enhancing the macrophage recruitment and increasing the ratio of IL-1 to IL-6, measured from the wound exudate collected 24 hours after wounding. IL-1 stimulates fibroblast growth and affects extracellular matrix composition through collagen generation and collagenase activation, while IL-6 promotes epidermal growth and inhibits fibroblast proliferation. Biafine is believed to have a positive effect on the formation of granulation tissue in fibroblasts by inducing the release of IL-1 and reducing the secretion of IL- $6 .{ }^{61}$

Application of biafine on full-thickness resection and burn wound models enhanced re-epithelization and accelerated closure. Histologically, biafine-treated wounds showed greater epidermal maturation, granulation tissue formation, and collagen quantity and quality. Treatment with biafine was associated with larger macrophage infiltration and lower neutrophil presence in the early stages of healing, which is crucial for acute and chronic skin wound healing. ${ }^{62} \mathrm{~A}$ study evaluating the effectiveness of biafine as a preventive agent for acute RISRs in women receiving RT of chest wall showed that biafine significantly reduced skin toxicity, although most of the patients developed grade 2 radiation dermatitis; and no delay or interruption in treatment was observed due to dermal toxicity. ${ }^{63}$

Collectively, these studies and the clinical observations have supported the therapeutic benefit of trolamine-containing topical emulsions for cutaneous ulcers and radiation dermatitis.

\section{Hydrogel and hydrocolloid dressings}

Hydrogel or hydrocolloid dressings are generally recommended for the treatment of mild acute skin wounds, from the surface to partial-thickness burns or chronic wounds, such as diabetic foot lesions or pressure sores. They increase the healing rate and reduce infection and pain. ${ }^{64}$ Hydrogel dressings do not adhere to wounds, and they are easy to clean and reuse. Hydrocolloid dressings are moisture retentive and self-adhesive, and they can be placed for a few days to simplify wound care ${ }^{65}$ When the hydrocolloid is placed on the wound, the area in direct contact absorbs the secretion and gradually forms a soft gel to keep the wound surface moist. This moisture promotes cell migration and assists in wound debridement through autolysis. The dressings can also prevent moisture from evaporating, allowing rehydration of the escharotic, which gradually liquefies and separates. Many studies have shown the benefits of the moist environment. ${ }^{66}$ Moreover, hydrocolloids are impermeable to oxygen and thus create an area of low oxygen tension on the wound surface, which can stimulate angiogenesis, thereby accelerating the growth of granulation tissue.

A few case reports have documented the use of hydrocolloid dressings on refractory wounds, including perineal burns after RT. They reported that hydrocolloid dressings have beneficial effects on healing, pain relief, comfort, and ease of use. ${ }^{67}$ Margolin et al conducted a study on 20 patients with hydrocolloidal dressing. The aim of the study was to determine whether moist occlusion healing improved the healing time, safety, and comfort for radiation-induced wounds. There was no obvious infection of the wound, and the average healing time is 12 days. It indicated that hydrocolloid dressing is effective in the treatment of radiation-induced skin wetting. ${ }^{65}$ 
Moist desquamation is the main cause of patient suffering, causing pain or discomfort and increasing the risk of infection. Gentian violet (GV) has been effective in the treatment of moist desquamation caused by RT. ${ }^{68}$ A trial compared GV and hydrogel dressings in treating moist desquamation caused by RT. The result showed that hydrogel dressings cured the moist desquamation induced by RT and are more tolerant than GV. ${ }^{69}$ In another trial, 60 patients receiving RT for head and neck cancer were assigned to hydrogel dressings or routine clinical practice for skin reactions. The result revealed that hydrogel dressings have a higher healing rate and less frequent occurrence of severe skin reactions than routine clinical practice. ${ }^{70}$

Therefore, hydrogel dressings appear to be promising in the treatment of acute radiation-induced skin wounds.

\section{Mesenchymal stem cells (MSCs)}

MSCs are important for regenerative medicine because of their strong ability of cytokine secretion, immunoregulation, and multipotential differentiation. The multipotential lineage of MSCs is characterized by the capacity for extracorporeal expansion and the ability to differentiate into bone, cartilage, and adipose tissues. ${ }^{71}$ MSCs from bone marrow have the highest proliferative capacity and maintain their pluripotency even after 50 passages. $^{72}$ MSCs have demonstrated accelerated healing of excisional wounds and thermal burns. ${ }^{73-76}$ Studies have shown that MSCs have protective effects on radiationinduced lung injury and vascular injury. ${ }^{72,77}$ More importantly, a lot of clinical trials have shown that intravenous injection of allogeneic human bone marrow MSCs (BMMSCs) is safe for patients. ${ }^{78}$

The role of MSCs in repairing different forms of RISRs has been extensively studied in animal models. Several groups have reported that locally injected MSCs are effective in healing ulcerative radiation wounds. ${ }^{79-81}$ Donor MSCs implanted in radiation lesions of irradiated mice differentiated into skin cells, leading to a partial understanding of the basic mechanisms of radiation-damaged skin regeneration observed in regenerating skin and hair follicle tissue. MSCs have been proposed to stimulate vascularization of these skin lesions, thereby increasing oxygen supply and helping immune cell recruitment. ${ }^{82}$ Shen et al revealed that the protective effect of MSCs are mainly through the inhibition of radiation-induced OS and inflammation, including the downregulation of TNF- $\alpha$, ICAM-1, TGF- $\beta$, and CTGF and the upregulation of antioxidant enzymes hemeoxygenase-1 and catalase in the radiation-induced damage model. ${ }^{72}$

Studies have also shown that the immunoregulatory properties of BMMSCs contribute to skin healing. ${ }^{83}$ An experi- ment demonstrated that the systemic infusions of BMMSCs could durably alter the progression of radiation-induced fibrosis by altering the macrophage phenotype and suppressing local inflammation. Immunohistochemical analysis showed that BMMSCs reduced the pro-inflammatory IL- $1 \beta$ levels, activated $\mathrm{CD} 80^{+}$macrophages, and increased the amount of anti-inflammatory IL-10 when irradiated mice were treated with systemic BMMSCs infusions. ${ }^{84}$ Currently, clinical data on the effects of MSCs on RISRs in humans are lacking. One Chinese case study reported about the treatment of a radiation with a combination of MSCs and hematopoietic stem cells, leading to the regeneration of radiation-induced skin ulcerations after 36 days. $^{85}$

MSCs may be a promising therapeutic approach to treat RISRs because of their powerful therapeutic function. But in recent years some people have suggested that cells called MSC may not really be stem cells. ${ }^{86}$ Whether MSCs can become the standard treatment for RISRs requires further study and experimental confirmation.

\section{Hyperbaric oxygen therapy (HBOT)}

Hyperbaric oxygen is defined as $100 \%$ oxygen at two to three times the atmospheric pressure at sea level, which can result in arterial oxygen tension in excess of $2,000 \mathrm{mmHg}$ and oxygen tension in tissue of almost $400 \mathrm{mmHg}$. Such doses of oxygen have many beneficial biochemical, cellular, and physiologic effects. ${ }^{87}$ HBOT is a relatively unknown treatment for delaying RISRs except for several small series and case reports that have been published. ${ }^{88,89}$ The role of hyperbaric oxygen in acute and subacute radiation injuries has not been well-studied or established, although researchers have shown interest in pursuing this application. ${ }^{90}$

Hyperbaric oxygen is thought to have complex effects on immunity, oxygen transportation, and hemodynamics, resulting in favorable therapeutic effects by reducing hypoxia and edema as well as enabling normal host responses to infection and ischemia. ${ }^{91}$ Since vascular obliteration and stromal fibrosis are the consistent cause and manifestation of radiation injury, the impact of hyperbaric oxygen in stimulating angiogenesis is an important mechanism against radiation injury. HBOT can induce neovascularization in hypoxic tissues. ${ }^{92}$ Marx ${ }^{93}$ have demonstrated enhanced vascularity and cellularity in heavily irradiated tissues after HBOT. They also demonstrated serial improvement in transcutaneous oxygen measurements of patients receiving hyperbaric oxygen as an indirect measure of increased vascular density.

According to the Undersea and Hyperbaric Medical Society, indications for HBOT include arterial insufficiency, 
refractory osteomyelitis, delayed radiation-induced soft tissue injury, and bone necrosis. HBOT has been recommended as a treatment for delayed radiation injury. ${ }^{94}$ In a randomized trial, a positive correlation was reported between tissue oxygenation and various markers of wound healing. ${ }^{95}$

In one case study, necrotic lesions induced by accidental radiation exposure improved after 140 sessions of HBOT without any adverse effects. ${ }^{96}$ Another study reported about the experience of delayed radiation injury in a single HBOTtreated gynecologic cancer patients. These patients with necrotic ulceration derive the most benefit from HBOT, and two of the four patients had completely healed ulcers. There was an improvement of $>50 \%$ in the other two patients. ${ }^{97}$ In another case, a female patient received treatment with HBOT a total of 101 times over the course of 1 year for a refractory skin ulcer after radical mastectomy and RT, and she completely recovered from the radiation-induced skin ulcer. ${ }^{98}$

HBOT has been applied as a therapy for delayed radiation injury for $>30$ years and considered as a good alternative for conservative treatment.

\section{Superoxide dismutase (SOD)}

OS is one of the main causes of RISRs. Antioxidant systems include enzymes, such as SOD, and glutathione peroxidase as well as peptides, such as glutathione. SOD is the first line of defense against OS pathological conditions because SOD can scavenge the ROS. ${ }^{33,99}$ Liposomal SOD is thought to downregulate TGF- $\beta$ expression in myofibroblasts and functions as an anti-inflammatory agent and antioxidant. ${ }^{24}$

Synthetic SOD with low molecular weight, low toxicity, low cost, and biological stability have opened new opportunities for therapeutic interventions against RISRs. ${ }^{100} \mathrm{~A}$ novel cyclized analog called EUK-207 is a synthetic SOD, which has a useful role in many OS models. A remarkable mitigation effect of EUK-207 on radiation-induced injury was noticed, including improvement in wound healing. By using 30 Gy of radiation dose without drug treatment, severe skin lesions could be induced that do not heal. At 48 hours after IR, EUK-207 was administered by hypodermic injection pump for up to 90 days. The rats treated with EUK-207 had reduced wet desquamation, lowered tissue inflammation, and enhanced wound contraction within 1 month. ${ }^{101}$

Clinical regression of fibrosis was seen at 2-month follow-up in a clinical trial of 34 patients treated with six intramuscular injections of SOD over a 3-week period. ${ }^{102}$ Reversal of radiation-induced skin fibrosis by liposomal $\mathrm{Cu} / \mathrm{Zn}-\mathrm{SOD}$ and Mn-SOD was observed after 6-month IR in an experimental swine model. It allowed correct tissue regeneration in established post-irradiation fibrotic regions. ${ }^{103}$

Therefore, SOD can be used as a new therapeutic method for the treatment of RISRs by generating an anti-OS environment.

\section{Low-intensity laser}

Laser therapy has been used as an assistant in the tissue repair process. Laser therapy photo activates cellular mechanisms, leading to the normalization of the affected region by promoting a reduction of edema, analgesia induction, and an acceleration of tissue repair. ${ }^{104,105}$ Therapeutic lasers provide low-energy density, which is sufficient for the target cells to stimulate the membrane or organelles. Laser radiation is absorbed by cytochromes in the mitochondria and converted into energy (ATP) by the cell, which plays a role in the acceleration or stimulation of protein synthesis and cell proliferation. Thus, the cell enters a state of photoperiod activation, in which it seeks to establish a normal state in the affected area, such as in the repair phase after tissue injury. ${ }^{106}$

Rezvani et $\mathrm{al}^{107}$ reported that low-intensity light exposure could reduce the necrosis of the dermis after X-ray exposure in animals. In a previous case report, three patients had undergone mastectomy for breast cancer and had refractory radiation ulcers on the skin. The radiation ulcers were treated with $30 \mathrm{~mW}$ helium-neon laser three times weekly and healed completely within $7.5-8$ weeks. ${ }^{108}$

For some intractable chronic RISRs, low-density laser therapy may become an advanced method in the future.

\section{Prevention of RISRs}

Prevention of RISRs is an important consideration in the pre- and post-RT period. First, proper skin hygiene is essential. Skin should be washed with mild soaps and lukewarm water to help maintain skin barrier, and it will decrease the risk for acute RISRs. ${ }^{109}$ Wear loose fitting clothing, avoid sun exposure, avoid metallic topical products, and use waterbased lipid-free moisturizers may help prevent post-RT complication. ${ }^{110}$ In addition to having therapeutic effects, topical corticosteroids have long been used to prevent RISRs. Corticosteroid use recommends application of low to medium potency steroids to the treatment field one to two times a day after each RT session to reduce the severity of acute RISRs and decrease the severity of symptoms. ${ }^{4}$ Oral Wobe-Mugus (a proteolytic enzyme made from a mixture of $100 \mathrm{mg}$ papain, $40 \mathrm{mg}$ trypsin, and $40 \mathrm{mg}$ chymotrypsin) has been shown to reduce the odds for developing RT-induced skin toxicity by as much as $87 \%$ in two non-blind RCTs vs no medication. ${ }^{111,112}$ 


\section{Conclusion}

Acute and chronic RISRs are the common side effects of RT. Inflammatory response and OS are the two main mechanisms of RISRs. The treatment of acute RISRs needs the formulation of relevant treatment strategies based on the degree of reactions. Traditional treatments, including topical steroids, creams, ointments, and hydrogel dressings, have been widely used in clinics. They have proved to have considerable therapeutic effects. Innovative treatment of acute RISRs still needs further study and confirmation. The treatment of chronic RISRs is more difficult. Many advanced treatments such as MSC, HBOT, SOD, and laser therapy are promising. However, a large number of clinical trials and studies are still required to validate their efficacy.

\section{Disclosure}

This report was supported in part by grants from the Norman Bethne Program of Jilin University (2015225 to Ying Xin and 2015203 to Xin Jiang), the Education Department of Jilin Province Foundations (2016-448 to Xin Jiang), the Jilin Provincial Science and Technology Foundations (20180414039 GH to Ying Xin and $220160414055 \mathrm{GH}$ to Xin Jiang), and the Health and Family Planning Commission of Jilin Province Foundations (2016Q034 to Ying Xin and 2015Q010 to Xin Jiang). The authors report no other conflicts of interest in this work.

\section{References}

1. Vaz AF, Pinto-Neto AM, Conde DM, Costa-Paiva L, Morais SS, Esteves SB. Quality of life of women with gynecologic cancer: associated factors. Arch Gynecol Obstet. 2007;276(6):583-589.

2. Chapel A, Francois S, Douay L, Benderitter M, Voswinkel J. Fifteen years of preclinical and clinical experiences about biotherapy treatment of lesions induced by accidental irradiation and radiotherapy. World $J$ Stem Cells. 2013;5(3):68-72.

3. Mendelsohn FA, Divino CM, Reis ED, Kerstein MD. Wound care after radiation therapy. Adv Skin Wound Care. 2002;15(5):216-224.

4. Hymes SR, Strom EA, Fife C. Radiation dermatitis: clinical presentation, pathophysiology, and treatment 2006. J Am Acad Dermatol. 2006;54(1):28-46.

5. Martin MT, Vulin A, Hendry JH. Human epidermal stem cells: role in adverse skin reactions and carcinogenesis from radiation. Mutat Res. 2016;770(Pt B):349-368.

6. Archambeau JO, Pezner R, Wasserman T. Pathophysiology of irradiated skin and breast. Int J Radiat Oncol Biol Phys. 1995;31(5):1171-1185.

7. Porock D. Factors influencing the severity of radiation skin and oral mucosal reactions: development of a conceptual framework. Eur $J$ Cancer Care (Engl). 2002;11(1):33-43.

8. Hu H, Nahas S, Gatti RA. Assaying radiosensitivity of ataxia-telangiectasia. Methods Mol Biol. 2017;1599:1-11.

9. Bernier J, Poortmans P. Clinical relevance of normal and tumour cell radiosensitivity in BRCA1/BRCA2 mutation carriers: a review. Breast. 2015;24(2):100-106

10. Shanley S, McReynolds K, Ardern-Jones A, et al. Acute chemotherapyrelated toxicity is not increased in BRCA1 and BRCA2 mutation carriers treated for breast cancer in the United Kingdom. Clin Cancer Res. 2006;12(23):7033-7038.
11. Park H, Choi DH, Noh JM, et al. Acute skin toxicity in Korean breast cancer patients carrying BRCA mutations. Int J Radiat Biol. 2014;90(1):90-94.

12. Najafi M, Motevaseli E, Shirazi A, et al. Mechanisms of inflammatory responses to radiation and normal tissues toxicity: clinical implications. Int J Radiat Biol. 2018;94(4):335-356.

13. Zhao W, Robbins ME. Inflammation and chronic oxidative stress in radiation-induced late normal tissue injury: therapeutic implications. Curr Med Chem. 2009;16(2):130-143.

14. Straub JM, New J, Hamilton CD, Lominska C, Shnayder Y, Thomas SM. Radiation-induced fibrosis: mechanisms and implications for therapy. J Cancer Res Clin Oncol. 2015;141(11):1985-1994.

15. Bray FN, Simmons BJ, Wolfson AH, Nouri K. Acute and chronic cutaneous reactions to ionizing radiation therapy. Dermatol Ther (Heidelb). 2016;6(2):185-206.

16. Peter RU. Diagnosis and treatment of cutaneous radiation injuries. In: Panizzonand RG, Seegenschmiedt MH, editors. Radiation Treatment and Radiation Reactions in Dermatology. Berlin, Heidelberg: Springer Berlin Heidelberg; 2015:185-188.

17. Janko M, Ontiveros F, Fitzgerald TJ, Deng A, DeCicco M, Rock KL. IL-1 generated subsequent to radiation-induced tissue injury contributes to the pathogenesis of radiodermatitis. Radiat Res. 2012;178(3): $166-172$.

18. Han R, Wu D, Deng S, Liu T, Zhang T, Xu Y. [NLRP3 inflammasome induces pyroptosis in lung tissues of radiation-induced lung injury in mice]. Xi Bao Yu Fen Zi Mian Yi Xue Za Zhi. 2017;33(9):1206-1211.

19. Shin D, Lee G, Sohn SH, et al. Regulatory T cells contribute to the inhibition of radiation-induced acute lung inflammation via bee venom phospholipase $\mathrm{A}_{2}$ in mice. Toxins (Basel). 2016;8(5):131.

20. Ahmad I, Muneer KM, Chang ME, et al. Ultraviolet radiation-induced downregulation of SERCA2 mediates activation of NLRP3 inflammasome in basal cell carcinoma. Photochem Photobiol. 2017;93(4): $1025-1033$.

21. Lamkanfi M. Emerging inflammasome effector mechanisms. Nat Rev Immunol. 2011;11(3):213-220.

22. Allam R, Lawlor KE, Yu EC, et al. Mitochondrial apoptosis is dispensable for NLRP3 inflammasome activation but non-apoptotic caspase-8 is required for inflammasome priming. EMBO Rep. 2014;15(9): 982-990.

23. Bentzen SM. Preventing or reducing late side effects of radiation therapy: radiobiology meets molecular pathology. Nat Rev Cancer. 2006;6(9):702-713.

24. Martin M, Lefaix J-L, Delanian S. TGF- $\beta 1$ and radiation fibrosis: a master switch and a specific therapeutic target? Int J Radiat Oncol Biol Phys. 2000;47(2):277-290.

25. Tibbs MK. Wound healing following radiation therapy: a review. Radiother Oncol. 1997;42(2):99-106.

26. Pohlers D, Brenmoehl J, Löffler I, et al. TGF-beta and fibrosis in different organs - molecular pathway imprints. Biochim Biophys Acta. 2009;1792(8):746-756.

27. Flanders $\mathrm{KC}$, Major $\mathrm{CD}$, Arabshahi A, et al. Interference with transforming growth factor-beta/Smad3 signaling results in accelerated healing of wounds in previously irradiated skin. Am J Pathol. 2003;163(6):2247-2257.

28. Chen MF, Chen WC, Lai CH, Hung CH, Liu KC, Cheng YH. Predictive factors of radiation-induced skin toxicity in breast cancer patients. BMC Cancer. 2010;10(1):508.

29. Meeran SM, Akhtar S, Katiyar SK. Inhibition of UVB-induced skin tumor development by drinking green tea polyphenols is mediated through DNA repair and subsequent inhibition of inflammation. $J$ Invest Dermatol. 2009;129(5):1258-1270.

30. Cheki M, Yahyapour R, Farhood B, et al. COX-2 in radiotherapy: a potential target for radioprotection and radiosensitization. Curr $\mathrm{Mol}$ Pharmacol. 2018;11(3):173-183.

31. Yahyapour R, Motevaseli E, Rezaeyan A. Reduction-oxidation (redox) system in radiation-induced normal tissue injury. Molecular Mechanisms and Implications in Radiation Therapeutics. Clin Transl Oncol. 2018;20(8):975-988. 
32. Najafi M, Shirazi A, Motevaseli E, Geraily G, Norouzi F, Heidari $\mathrm{M}$, Rezapoor $\mathrm{S}$. The melatonin immunomodulatory actions in radiotherapy. Biophys Rev. 2017;9(2):139-148.

33. Vorotnikova E, Rosenthal RA, Tries M, Doctrow SR, Braunhut SJ. Novel synthetic SOD/catalase mimetics can mitigate capillary endothelial cell apoptosis caused by ionizing radiation. Radiat Res. 2010;173(6):748-759.

34. Bae YS, Oh H, Rhee SG, Yoo YD. Regulation of reactive oxygen species generation in cell signaling. Mol Cells. 2011;32(6):491-509.

35. Dent P, Yacoub A, Fisher PB, Hagan MP, Grant S. MAPK pathways in radiation responses. Oncogene. 2003;22(37):5885-5896.

36. Drummond GR, Selemidis S, Griendling KK, Sobey CG. Combating oxidative stress in vascular disease: NADPH oxidases as therapeutic targets. Nat Rev Drug Discov. 2011;10(6):453-471.

37. Panday A, Sahoo MK, Osorio D, Batra S. NADPH oxidases: an overview from structure to innate immunity-associated pathologies. Cell Mol Immunol. 2015;12(1):5-23.

38. Aktan F. iNOS-mediated nitric oxide production and its regulation. Life Sci. 2004;75(6):639-653.

39. Ohta S, Matsuda S, Gunji M, Kamogawa A. The role of nitric oxide in radiation damage. Biol Pharm Bull. 2007;30(6):1102-1107.

40. Pugin J. How tissue injury alarms the immune system and causes a systemic inflammatory response syndrome. Ann Intensive Care. 2012;2(1):27.

41. Frey B, Rückert M, Deloch L, Rühle PF, Derer A, Fietkau R, Gaipl US. Immunomodulation by ionizing radiation-impact for design of radio-immunotherapies and for treatment of inflammatory diseases. Immunol Rev. 2017;280(1):231-248.

42. Yahyapour R, Amini P, Rezapoor S, et al. Targeting of inflammation for radiation protection and mitigation. Curr Mol Pharmacol. 2018;11(3):203-210.

43. López E, Guerrero R, Núñez MI, et al. Early and late skin reactions to radiotherapy for breast cancer and their correlation with radiation-induced DNA damage in lymphocytes. Breast Cancer Res 2005;7(5):R690-698.

44. Lomax ME, Folkes LK, O’Neill P. Biological consequences of radiation-induced DNA damage: relevance to radiotherapy. Clin Oncol (R Coll Radiol). 2013;25(10):578-585.

45. Dedon PC, Tannenbaum SR. Reactive nitrogen species in the chemical biology of inflammation. Arch Biochem Biophys. 2004;423(1):12-22.

46. Jaiswal M, Larusso NF, Burgart LJ, Gores GJ. Inflammatory cytokines induce DNA damage and inhibit DNA repair in cholangiocarcinoma cells by a nitric oxide-dependent mechanism. Cancer Res. 2000;60(1):184-190.

47. Meghrajani CF, Co HC, Ang-Tiu CM, Roa FC. Topical corticosteroid therapy for the prevention of acute radiation dermatitis: a systematic review of randomized controlled trials. Expert Rev Clin Pharmacol. 2013;6(6):641-649.

48. Boström A, Lindman H, Swartling C, Berne B, Bergh J. Potent corticosteroid cream (mometasone furoate) significantly reduces acute radiation dermatitis: results from a double-blind, randomized study. Radiother Oncol. 2001;59(3):257-265.

49. Kupper TS. The activated keratinocyte: a model for inducible cytokine production by non-bone marrow-derived cells in cutaneous inflammatory and immune responses. J Invest Dermatol. 1990;94(6 Suppl):146S-150S

50. Brach MA, Gruss HJ, Kaisho T, Asano Y, Hirano T, Herrmann F. Ionizing radiation induces expression of interleukin 6 by human fibroblasts involving activation of nuclear factor-kappa B. J Biol Chem 1993;268(12):8466-8472.

51. Beetz A, Messer G, Oppel T, van Beuningen D, Peter RU, Kind P. Induction of interleukin 6 by ionizing radiation in a human epithelial cell line: control by corticosteroids. Int J Radiat Biol. 1997;72(1):33-43.

52. Moriyasu S, Yamamoto K, Kureyama N, Okamura K, Ikeda T, Yamatodani A. Involvement of histamine released from mast cells in acute radiation dermatitis in mice. J Pharmacol Sci. 2007;104(2): 187-190.
53. Barton J, Lavker RM, Schechter NM, Lazarus GS. Treatment of urticaria pigmentosa with corticosteroids. Arch Dermatol. 1985;121(12): 1516-1523.

54. Miller RC, Schwartz DJ, Sloan JA, et al. Mometasone furoate effect on acute skin toxicity in breast cancer patients receiving radiotherapy: a phase III double-blind, randomized trial from the North Central Cancer Treatment Group N06C4. Int J Radiat Oncol Biol Phys. 2011;79(5):1460-1466.

55. Schmuth M, Wimmer MA, Hofer S, et al. Topical corticosteroid therapy for acute radiation dermatitis: a prospective, randomized, double-blind study. Br J Dermatol. 2002;146(6):983-991.

56. Omidvari S, Saboori H, Mohammadianpanah M, et al. Topical betamethasone for prevention of radiation dermatitis. Indian J Dermatol Venereol Leprol. 2007;73(3):209.

57. Ulff E, Maroti M, Serup J, Falkmer U. A potent steroid cream is superior to emollients in reducing acute radiation dermatitis in breast cancer patients treated with adjuvant radiotherapy. A randomised study of betamethasone versus two moisturizing creams. Radiother Oncol. 2013;108(2):287-292.

58. Del Rosso JQ, Bikowski J. Trolamine-containing topical emulsion: clinical applications in dermatology. Cutis. 2008;81(3):209-214.

59. Harper JL, Franklin LE, Jenrette JM, Aguero EG. Skin toxicity during breast irradiation: pathophysiology and management. South Med J. 2004;97(10):989-993.

60. Glesinger R, Cohen AD, Bogdanov-Berezovsky A, Krieger Y, Rosenberg L. A randomized controlled trial of silver sulfadiazine, biafine, and saline-soaked gauze in the treatment of superficial partial-thickness burn wounds in pigs. Acad Emerg Med. 2004;11(4):339-342.

61. Coulomb B, Friteau L, Dubertret L. Biafine applied on human epidermal wounds is chemotactic for macrophages and increases the IL1/ IL6 ratio. Skin Pharmacol Physiol. 1997;10(5-6):281-287.

62. Krausz AE, Adler BL, Landriscina A, Rosen JM, Musaev T, Nosanchuk JD, Friedman AJ. Biafine topical emulsion accelerates excisional and burn wound healing in mice. Arch Dermatol Res. 2015;307(7):583-594.

63. Szumacher E, Wighton A, Franssen E, et al. Phase II study assessing the effectiveness of Biafine cream as a prophylactic agent for radiation-induced acute skin toxicity to the breast in women undergoing radiotherapy with concomitant CMF chemotherapy. Int J Radiat Oncol Biol Phys. 2001;51(1):81-86.

64. Wasiak J, Cleland H, Campbell F, Spinks A. Dressings for superficial and partial thickness burns. Cochrane Database Syst Rev. 2013;3:CD002106.

65. Margolin SG, Breneman JC, Denman DL, Lachapelle P, Weckbach L, Aron BS. Erratum: management of radiation-induced moist skin desquamation using hydrocolloid dressing. Cancer Nurs. 1990;13(4):267-280.

66. Fisher J, Scott C, Stevens R, et al. Randomized phase III study comparing Best Supportive Care to Biafine as a prophylactic agent for radiation-induced skin toxicity for women undergoing breast irradiation: Radiation Therapy Oncology Group (RTOG) 97-13. Int J Radiat Oncol Biol Phys. 2000;48(5):1307-1310.

67. Panasiti V, Devirgiliis V, Borroni RG, et al. Management of skin ulcers in a patient with mycosis fungoides. Dermatol Online J. 2006;12(2):16.

68. Naylor W, Mallett J. Management of acute radiotherapy induced skin reactions: a literature review. Eur J Oncol Nurs. 2001;5(4):221-233.

69. Gollins S, Gaffney C, Slade S, Swindell R. RCT on gentian violet versus a hydrogel dressing for radiotherapy-induced moist skin desquamation. J Wound Care. 2008;17(6):268-275.

70. Censabella S, Claes S, Orlandini M, Braekers R, Thijs H, Bulens P. Retrospective study of radiotherapy-induced skin reactions in breast cancer patients: reduced incidence of moist desquamation with a hydroactive colloid gel versus dexpanthenol. Eur J Oncol Nurs. 2014;18(5):499-504.

71. Dominici M, Le Blanc K, Mueller I, et al. Minimal criteria for defining multipotent mesenchymal stromal cells. The International Society for Cellular Therapy position statement. Cytotherapy. 2006;8(4):315-317.

72. Shen Y, Jiang X, Meng L, Xia C, Zhang L, Xin Y. Transplantation of bone marrow mesenchymal stem cells prevents radiation-induced artery injury by suppressing oxidative stress and inflammation. Oxid Med Cell Longev. 2018;2018(3):1-13. 
73. Landry Y, Le O, Mace KA, Restivo TE, Beauséjour CM. Secretion of SDF-1alpha by bone marrow-derived stromal cells enhances skin wound healing of $\mathrm{C} 57 \mathrm{BL} / 6$ mice exposed to ionizing radiation. $J$ Cell Mol Med. 2010;14(6B):1594-1604.

74. Jackson WM, Nesti LJ, Tuan RS. Mesenchymal stem cell therapy for attenuation of scar formation during wound healing. Stem Cell Res Ther. 2012;3(3):20.

75. Heo SC, Jeon ES, Lee IH, Kim HS, Kim MB, Kim JH. Tumor necrosis factor- $\alpha$-activated human adipose tissue-derived mesenchymal stem cells accelerate cutaneous wound healing through paracrine mechanisms. J Invest Dermatol. 2011;131(7):1559-1567.

76. Ding J, Hori K, Zhang R, Marcoux Y, Honardoust D, Shankowsky HA, Tredget EE. Stromal cell-derived factor 1 (SDF-1) and its receptor CXCR4 in the formation of postburn hypertrophic scar (HTS). Wound Repair Regen. 2011;19(5):568-578.

77. Klein D, Steens J, Wiesemann A, et al. Mesenchymal stem cell therapy protects lungs from radiation-induced endothelial cell loss by restoring superoxide dismutase 1 expression. Antioxid Redox Signal. 2017;26(11):563-582.

78. Xin Y, Jiang $\mathrm{X}$, Wang $\mathrm{Y}$, et al. Insulin-producing cells differentiated from human bone marrow mesenchymal stem cells in vitro ameliorate streptozotocin-induced diabetic hyperglycemia. PLoS One. 2016;11(1):e0145838.

79. Agay D, Scherthan H, Forcheron F, Grenier N, Hérodin F, Meineke V, Drouet M. Multipotent mesenchymal stem cell grafting to treat cutaneous radiation syndrome: development of a new minipig model. Exp Hematol. 2010;38(10):945-956.

80. Akita S, Akino K, Hirano A, Ohtsuru A, Yamashita S. Mesenchymal stem cell therapy for cutaneous radiation syndrome. Health Phys. 2010;98(6):858-862.

81. Lataillade JJ, Doucet C, Bey E, et al. New approach to radiation burn treatment by dosimetry-guided surgery combined with autologous mesenchymal stem cell therapy. Regen Med. 2007;2(5): 785-794.

82. Nicolay NH, Lopez Perez R, Debus J, Huber PE. Mesenchymal stem cells - a new hope for radiotherapy-induced tissue damage? Cancer Lett. 2015;366(2):133-140.

83. de Mayo T, Conget P, Becerra-Bayona S, Sossa CL, Galvis V, ArangoRodríguez ML. The role of bone marrow mesenchymal stromal cell derivatives in skin wound healing in diabetic mice. PLoS One. 2017;12(6):e0177533.

84. Horton JA, Hudak KE, Chung EJ, White AO, Scroggins BT, Burkeen JF, Citrin DE. Mesenchymal stem cells inhibit cutaneous radiationinduced fibrosis by suppressing chronic inflammation. Stem Cells. 2013;31(10):2231-2241.

85. Guo M, Dong Z, Qiao J, et al. Severe acute radiation syndrome: treatment of a lethally 60Co-source irradiated accident victim in China with HLA-mismatched peripheral blood stem cell transplantation and mesenchymal stem cells. J Radiat Res. 2014;55(2):205-209.

86. Caplan AI. Mesenchymal stem cells: time to change the name! Stem Cells Transl Med. 2017;6:1445-1451.

87. Tibbles PM, Edelsberg JS. Hyperbaric-oxygen therapy. N Engl J Med. 1996;334:1642-1648.

88. Baert J, Carpentier P, Garcia RB, et al. Hyperbaric oxygen treatment for radiation ulcer of the bladder. Br J Urol. 1998;81:929-930.

89. Warren DC, Feehan P, Slade JB, Cianci PE. Chronic radiation proctitis treated with hyperbaric oxygen. Undersea Hyperb Med. 1997;24(3):181-184.

90. Carl UM, Hartmann KA. Hyperbaric oxygen treatment for symptomatic breast edema after radiation therapy. Undersea Hyperb Med. 1998;25(4):233-234.

91. Grim PS. Hyperbaric oxygen therapy. JAMA. 1990;263(16):2216-2220.

92. Feldmeier JJ. Hyperbaric oxygen therapy and delayed radiation injuries (soft tissue and bony necrosis): 2012 update. Undersea Hyperb Med. 2012;39(6):1121-1139.

93. Marx RE. Osteoradionecrosis: a new concept of its pathophysiology. J Oral Maxillofac Surg. 1983;41(5):283-288.
94. Feldmeier JJ, Heimbach RD, Davolt DA, Court WS, Stegmann BJ, Sheffield PJ. Hyperbaric oxygen as an adjunctive treatment for delayed radiation injury of the chest wall: a retrospective review of twenty-three cases. Undersea Hyperb Med. 1995;22(4):383-393.

95. Kaur S, Pawar M, Banerjee N, Garg R. Evaluation of the efficacy of hyperbaric oxygen therapy in the management of chronic nonhealing ulcer and role of periwound transcutaneous oximetry as a predictor of wound healing response: a randomized prospective controlled trial. $J$ Anaesthesiol Clin Pharmacol. 2012;28(1):70-75.

96. Yildiz S, Cimsit M, Ilgezdi S, Uzun G, Gumus T, Qyrdedi T, Dalci D. Hyperbaric oxygen therapy used to treat radiation injury: two case reports. Ostomy Wound Manage. 2006;52(5):14-16.

97. Fink D, Chetty N, Lehm JP, Marsden DE, Hacker NF. Hyperbaric oxygen therapy for delayed radiation injuries in gynecological cancers. Int J Gynecol Cancer. 2006;16(2):638-642.

98. Enomoto M, Yagishita K, Okuma K, et al. Hyperbaric oxygen therapy for a refractory skin ulcer after radical mastectomy and radiation therapy: a case report. J Med Case Rep. 2017;11(1):5.

99. Batinić-Haberle I, Rebouças JS, Spasojević I. Superoxide dismutase mimics: chemistry, pharmacology, and therapeutic potential. Antioxid Redox Signal. 2010;13(6):877-918.

100. Rebouças JS, Spasojevic' I, Batinic'-Haberle I. Pure manganese(III) 5,10,15,20-tetrakis(4-benzoic acid)porphyrin (MnTBAP) is not a superoxide dismutase mimic in aqueous systems: a case of structureactivity relationship as a watchdog mechanism in experimental therapeutics and biology. J Biol Inorg Chem. 2008;13(2):289-302.

101. Rosenthal RA, Fish B, Hill RP, et al. Salen Mn complexes mitigate radiation injury in normal tissues. Anticancer Agents Med Chem. 2011;11(4):359-372.

102. Delanian S, Baillet F, Huart J, Lefaix JL, Maulard C, Housset M. Successful treatment of radiation-induced fibrosis using liposomal $\mathrm{Cu} / \mathrm{Zn}$ superoxide dismutase: clinical trial. Radiother Oncol. 1994;32(1):12-20.

103. Lefaix JL, Delanian S, Leplat JJ, et al. Successful treatment of radiation-induced fibrosis using $\mathrm{Cu} / \mathrm{Zn}$-SOD and Mn-SOD: an experimental study. Int J Radiat Oncol Biol Phys. 1996;35(2):305-312.

104. Tumilty S, Munn J, Abbott JH, McDonough S, Hurley DA, Baxter GD. Laser therapy in the treatment of achilles tendinopathy: a pilot study. Photomed Laser Surg. 2008;26(1):25-30.

105. Yasukawa A, Hrui H, Koyama Y, Nagai M, Takakuda K. The effect of low reactive-level laser therapy (LLLT) with helium-neon laser on operative wound healing in a rat model. JVet Med Sci. 2007;69(8):799-806.

106. da Silva JP, da Silva MA, Almeida AP, Lombardi Junior I, Matos AP. Laser therapy in the tissue repair process: a literature review. Photomed Laser Surg. 2010;28(1):17-21.

107. Rezvani M, Robbins ME, Hopewell JW, Whitehouse EM. Modification of late dermal necrosis in the pig by treatment with multi-wavelength light. Br J Radiol. 1993;66(782):145-149.

108. Schindl A, Schindl M, Pernerstorfer-Schön H, Mossbacher U, Schindl L. Low intensity laser irradiation in the treatment of recalcitrant radiation ulcers in patients with breast cancer--long-term results of 3 cases. Photodermatol Photoimmunol Photomed. 2000;16(1):34-37.

109. Roy I, Fortin A, Larochelle M. The impact of skin washing with water and soap during breast irradiation: a randomized study. Radiother Oncol. 2001;58(3):333-339.

110. Bernier J, Bonner J, Vermorken JB, et al. Consensus guidelines for the management of radiation dermatitis and coexisting acne-like rash in patients receiving radiotherapy plus EGFR inhibitors for the treatment of squamous cell carcinoma of the head and neck. Ann Oncol. 2008;19(1):142-149.

111. Dale PS, Tamhankar CP, George D, Daftary GV. Co-medication with hydrolytic enzymes in radiation therapy of uterine cervix: evidence of the reduction of acute side effects. Cancer Chemother Pharmacol. 2001;47(Suppl):S29-S34.

112. Gujral MS, Patnaik PM, Kaul R, Parikh HK, Conradt C, Tamhankar $\mathrm{CP}$, Daftary GV. Efficacy of hydrolytic enzymes in preventing radiation therapy-induced side effects in patients with head and neck cancers. Cancer Chemother Pharmacol. 2001;47(Suppl):S23-S28. 
Cancer Management and Research

\section{Publish your work in this journal}

Cancer Management and Research is an international, peer-reviewed open access journal focusing on cancer research and the optimal use of preventative and integrated treatment interventions to achieve improved outcomes, enhanced survival and quality of life for the cancer patient.

The manuscript management system is completely online and includes

Submit your manuscript here: https://www.dovepress.com/cancer-management-and-research-journal 